\title{
Municipal Government Use of Social Media: An Analysis of Three Chinese Cities*
}

\author{
Tiejun Gu \\ Donghua University \\ tigu@dhu.edu.cn
}

\author{
Teresa M. Harrison \\ University at Albany, SUNY \\ tharrison@albany.edu
}

\author{
Yani Zhu \\ Donghua University \\ yanizhu@,mail.dhu.edu.cn
}

\begin{abstract}
To investigate the use of information dissemination and public communication by Chinese municipal governments, we analyzed the social media use of three large cities with relatively mature social media development: Shanghai, Nanjing and Chengdu. We collected 4,429 government posts and users' likes, shares and comments from Weibo accounts of each city's information office. Government posts were coded into 7 types and 16 topics. We used cross-tabulation, correlation analysis and multivariate linear regression to analyze government posts, user responses and their inter-relationships. Chengdu issued the most posts; Nanjing received the highest average user response to posts and exhibited the best signs of success in communication between the government and citizens.
\end{abstract}

\section{Introduction}

The emergence of social media has triggered a change in communication with a considerable impact on developing countries such as China. At present, social media have become one of the most important sources of information for many Chinese, especially young people, and also a new channel of communication for government information disclosure, image construction, and public dialogue.

Among the first and still most important social media channels to appear in China is Weibo. By the end of 2018, Weibo's users have exceeded 350 million, an increase of $10.9 \%$ over the previous year, and the usage rate by Internet users has reached $42.3 \%$. The Chinese government opened an account on Weibo at the end of 2009. So far, it has developed more than 130,000 certified Weibo government channels, involving national, provincial, municipal and county

*This work was also supported by the China Scholarship Council and CTG, University at Albany, SUNY.

URI: https://hdl.handle.net/10125/63962

978-0-9981331-3-3

(CC BY-NC-ND 4.0) levels, and different functional agencies. Among those that play a role in public information dissemination are the main accounts of local governments, and those of other administrative departments; together they form a government microblog matrix in which departments are not only relatively independent, but also contribute to the main account. Major government information, special events announcements, and city development notices are issued simultaneously through the public information account and related functional accounts.

To enhance social and administrative governance, China's central government has continuously promoted top-down information disclosure advising government units to make such disclosure "visible, understandable, supervisory and participatory"[8]. Social media is a new channel for the government to distribute information and interact with the public [9]. From the perspective of communication, the Chinese government is also aware of the importance of new media, and seeks to accelerate the integration and development of traditional media and new media [25], so as to strengthen mainstream media's influence and credibility. There are some indications that certain democratic practices are valued and in fact encouraged in China. The government hopes to use social platforms to reduce information asymmetry, reach out to the public, assess public opinion, establish good public relations and even adopt people's opinions to assist its decision-making to maintain political and social stability, and boost economic development [24]. Scholars have made the point that the central government can even be seen to encourage public comments on social media as long as there is no advocacy of collective action [13]. As Schlæger and Jiang [23] point out, the central government does not impose constraints on cities for conducting social media discourse; instead each city can formulate their own guidelines. Thus each municipality microblog can be seen as a "beta-institution" or a kind of experiment in which the interaction reflects the different conditions under which each social media channel operates [23]. In this way, the central government can observe the 
results and learn from each city's experiment in social media discourse. Of course, netizens are often quite willing to use public platforms to express their thoughts freely and quickly, so as to realize political participation and express opinions that are difficult to voice in traditional ways. This raises an important question for analysis: In the context of China's large cities, have municipal governments succeeded in facilitating this communication using social media? Further, based on the information released by the government, how has the public responded?

A variety of approaches to the study of social media communication between government and citizens have now appeared in the research literature. A classic study was Mergel's study [18] of social media interaction in the public sector. She observed government's use of three strategies: one-way push of information to users, two-way pull of information from users, and networking/co-design of services with users, which corresponded to three major tasks of Open Government policy promoted by the Obama administration: transparency, participation and collaboration. With this work as a model, Wukich and Mergel [26] proposed one-to-many, one-to-one, and many-to-many communication tactics for state-level emergency management agencies in different stages of crisis management. DePaula and Dincelli [4] added impression management to the three modes of egovernment interactivity, noting that government does not simply provide information, but also seeks to represent itself in favorable ways in doing so, thus enacting a form of public relations. Other research has found that characteristics of interactivity, such as depth and breadth, are determined by structural and content features [11], and that population size, socio-economic status, and location affects the scope, volume of activity and engagement on Facebook [15]. Li et al. [16] developed a research model for mobile government microblogging services in which citizens' perceived integration of online and offline social lives and internet censorship were incorporated.

We selected Weibo accounts of three Chinese municipal government information offices as research objects, and observed two months of government's use of social media to provide information and enable subsequent public participation. Starting with the classification of government social media posts, we then analyze and compare the three municipal government's posts, exploring the preferences of each in publishing particular types and topics of information, as well as reactions to these posts by the public. This paper is organized as follows: Following this introduction, Section 2 explores research perspectives on government social media and presents the research questions. Section 3 describes our methods for data collection, classification and coding for the posts of the municipal government Weibo accounts in China, and our data analysis methods. Section 4 presents the results of our data analysis. Section 5 explains these results, discusses theoretical implications, limitations of the study, and recommendations for government decision-making. Section 6 summarizes our conclusions and suggestions for future research to build on what we have learned.

\section{Government Use of Social Media}

Social media makes it possible, in principle, to conduct exchanges between government and citizens through a cyclical communication mode of government post and user response. This presents the potential to produce various forms of government-citizen interaction, as implied by the three strategies of push, pull, and networking of participants proposed by Mergel [18], enriched and expanded by Wukich and Mergel [26], and DePaula and Dincelli [4]. Different research approaches have subsequently emerged, however, one-way push strategies predominate in social media [19]. Existing research tells us that the online communication behavior of local governments is based on disseminating information in a traditional way, without adapting their habits to the particular affordances of SNSs [19][12]. Local governments use Facebook in a top-down manner [14], with most posts pushing information about policy or department related matters; collaborative or networking activity is adopted less than $10 \%$ of the time [4]. One notable exception is Twitter, which shows evidence of networking and pull outcomes [19]. Further, some state-level emergency management agencies employed interactive approaches in social media to increase public participation and promote behavioral change [26].

However, the one-way push strategy is still the primary means of communication for governments using social media platforms. What kinds of information does the government tend to release? No uniform standard for categories of government-issued messages has been developed, either based on the classic communication strategies [14][4][5], or on differences in content, structure and media characteristics of the posts [12][2][11]. Using different classification schemes may lead the research results in different directions if there is no effort to overlap or extend upon each other. At the same time, the types and topics of posts are likely to differ based upon the geographic and cultural attributes of the local government. In our research, we combined two key characteristics of government posts: the type of post, based on what it appears the government is trying to do 
in issuing a post (e.g., providing information, making an announcement, requesting feedback, etc.) and the specific topic areas covered by the post. Our goal is to observe government posting preferences from these two typologies, and lay the foundation for linking them to subsequent public responses. Our classification schemes will be discussed in section 3.2.

It is worth mentioning that, for the classification of communication types, we added the post type of "Guidance" to our categories of Chinese municipal government social media posts. This category, in which government seeks to provide advice to citizens related to various civic choices, is geared to the rapid urbanization and social changes in China. Many domestic famers from rural areas are flooding into metropolises such as Shanghai, Nanjing and Guangzhou, which also attract talented people from all over the world who cherish the pursuit of a better life or career development, and hope to take root in these metropolises. Adapting to a new region, norms, culture, and environment presents enormous challenges to these new immigrants. Given different backgrounds and living habits, integration into a new and different urban life can be daunting. Social media posts that offer "Guidance" reflect the authoritative and caring guiding role of municipal governments in educating newcomers about public values, behavioral norms, and even psychological emotions.

To compare the posting preferences of governments in three Chinese cities' social media accounts, two research questions are proposed:

RQ1. What types of government social media posts are chosen by the three cities?

RQ2. What are the differences in topics addressed in government social media posts by the three cities?

It next makes sense to ask about the public's reaction to the messages released by the government. The highest level of government-citizen interaction is the collaborative formation of policy and social management through social media, however it is not clear if the Chinese public hopes to engage in dialogue with the government to achieve such goals. Public responses to posts can usually be measured by likes, shares and comments [14][6]. Previous studies have shown that interaction between government and citizens on government social platforms is insufficient and imbalanced, but not non-existent. Evaluating two different levels of public engagement of Italian local government, Agostino and Arnaboldi [1] found that city administrations are more disposed to use social media for promoting unidirectional communication than for public participation purposes. For China's Weibo platform, the interactions between governments and the public in government microblog accounts were viewed as mostly insufficient and preliminary [28].
Similarly, the use of government-managed Weibo accounts is less dialogical and less creative than general Weibo use [17]. Imbalance is reflected in the study of local governments in Greece, which seem to perform well on Facebook by posting content that is liked and shared by citizens, but they do not score high in engaging citizens through online commenting [14]. Of course, different types of government posts may attract different levels of public response.

A few studies explicitly examine the effectiveness of government's attempts to foster interaction and dialogue with citizens. DePaula and Dincelli [6] highlight the affective and symbolic nature of social media, but also point to higher levels of interaction in instances where governments themselves engage in dialogue with citizens. Posts that reflected symbolic presentation and dialogue/interaction received significantly more likes and comments. Lappas et al. [14] found that impression management is an effective strategy that encourages citizens' online attitude expression as well as advocacy behavior. GálvezRodríguez et al. [7] examined social media activities of Latin American local governments and confirmed that dialogic strategies favor citizens' engagement.

However, it is also the case that government's posting tendencies may not be necessarily highly related to public response. For example, Bonsón, et al. [2] found that cultural activities, sports, and marketing topics are the most widely posted by Western European local governments, but these topics do not seem to be the most relevant for citizens. Agostino and Arnaboldi [1] showed that city government posts on Facebook do not always result in better engagement; citizens will instead ignore this information overload. Finally, public participation can be affected by a variety of factors. Sentiment or tone [27][3], multimedia elements and external links [11], multimedia features [12][11], originality [11], and even external advertisements [12] may have an impact on interaction, although research has not produced good estimates of the degree of impact.

In this research, we asked how government social media posts in Chinese metropolitan areas are related to citizen responses. To compare public response to government social media posts in our three cities, and to explore the relationship between posting categories and responses, these research questions are proposed: RQ3. What are the differences in public responses to government social media between the three cities?

RQ4. Is the type and topic of Chinese municipal government posts consistent with public interest, as reflected by likes, shares, and comments? What types or topics are more attractive to citizens of each city?

\section{Methods}




\subsection{Data collection}

We collected relevant data from Sina Weibo, China's largest microblogging platform. The average daily release of Sina Weibo is over 250 million texts and images. As the platform with the earliest start, most mature development, and most open atmosphere in new government media [22], China's government Weibo has gathered more than 380 billion readings in 2018; thus it has become an important channel for government to carry out online communication and public participation practices.

The microblog accounts of the information offices of Shanghai, Nanjing and Chengdu were selected for three reasons. First, according to the People's Daily Public Opinion Monitoring Office in China, and the report on the microblog influence of government index jointly issued by People's Daily and Sina Weibo [22][21][20], these cities consistently rank within China's top ten information office microblogs in the past three years.

Second, Shanghai, Nanjing and Chengdu are all super-large cities in China, with a population of 24.23, 8.335 , and 16.33 million respectively in 2018. But due to geography, history, culture, economy and other developments, the three cities possess distinctive characteristics. Shanghai is an international metropolis with a diversified, modern and fashionable city image of compassion and inclusiveness, and seeks to be seen as a world first-class city as its development goal. Nanjing has a profound historical and cultural heritage. As the ancient capital of China's six dynasties, it is an important part of the Chinese Han civilization, and a witness to the process of modern Chinese history. Chengdu is a typical example of the leisure cities in the Midwest of China. In recent years, due to cultural characteristics such as teahouse, pandas, wine, and hot pot, Chengdu is becoming more attractive.

Third, since the public information account is usually the earliest channel, with the broadest range and stability of its user group, these city accounts are more mature and have high credibility and influence.

We collected all the government posts and public responses of the three cities' information accounts from October 1, 2018 to November 30, 2018. The total number of posts was 4,429 . The total number of public responses was 403,764, reflecting the addition of likes, shares, and comments. The average frequency of daily posts of Shanghai, Nanjing and Chengdu was 21, 15, and 36 posts respectively.

\subsection{Post Categories}

Sina Weibo stipulates that users other than microblog owners are not allowed to make posts in microblog accounts; they can only submit comments in the form of a follow-up post if they wish to respond. As a result, the posts become one of the most important government social actions that trigger interaction. To analyze the characteristics of and public preferences for posts published by each city, we first classified the posts systematically.

Two classification perspectives were used; one is derived from taxonomies based on the interactive framework, such as Lappas et al. [14]'s five categories (transparency, marketing of events, information provision, impression management, and co-design) that represented the general communication strategies used by local government, and DePaula, et al.'s [5] typology of government communication on social media (information provision, input seeking, online dialogue and offline interaction, symbolic presentation). Combining these with the special practice of Guidance in China, we divided the posts into 7 category types with the following definitions:

- Publicity: Image, text or video creating favorable impressions of the city

- Guidance: Advice about values and behaviors

- Information disclosure: Government affairs, policies, statistics, environmental monitoring data

- Reminders: Related to people's livelihood

- Announcements: Important upcoming events

- Interaction: Seeking citizen participation, such as survey, vote, consultation, lottery

- Other: Miscellaneous types

Second, because the three cities are relatively large in scale, and urban development, civic life and events are complex and diverse, we classified the specific topic areas that municipal governments are concerned about into 16 categories, namely:

- Transportation: Road traffic, construction

- Education:Schools, exams, teacher-student-parent

- Health: Health care

- Food: Food, restaurants, recipes

- Weather: Weather forecasts, warnings

- Sports: Sports activity, competition, fitness

- Tourism: Travel recommendations, landscape depiction, photography

- Environment: Environmental protection

- Employment: Employment and job searching

- Art: History, literature, art

- Recreation: Funny story, entertainment

- Society: News, sensational events, emergencies

- Life: personal life

- Government: Government affairs

- Industry: Economic development

- Other: Miscellaneous topics 


\subsection{Coding}

A detailed set of coding instructions was produced. The instructions consist of general coding principles, description of each category (including definition, scope, and examples), exceptions, and precautions. After preliminary coding instruction, $10 \%$ of the total posts data set from each of the three cities was randomly extracted. Two coders carried out a pilot study of coding. The coding instruction was then revised and supplemented based on the pilot results, and gradually formed a formal one. Next, $10 \%$ of the total data from each city was extracted, excluding the data used in the pilot study, and formal coding was performed. Using Krippendorff's alpha test, the intercoder reliability of the type categories was 0.83 ; the intercoder reliability of the topic categories was 0.78 . Since these were acceptable outcomes, the coders divided the remaining coding.

\subsection{Analytical Methods}

To answer RQ1 and 2, we analyzed differences in the postings within and between cities through crosstabulations for the three cities and 7 message types or 16 message topics, and conducted chi-square tests. For RQ3, public responses were measured by adding likes, shares and comments as a single overall indicator, producing total responses for each government post. Further, considering the impact of the different post frequencies for different categories on the overall response, the cross-tabulations of RQ3 were constructed by using the average number of responses for posts in each category (the total number of responses in a category/the number of posts in the same category), to compare differences within and between cities. Regarding RQ4, correlation analysis explored whether there was consistency between the number of posts in the message types and topics and subsequent public interest reflected by total responses and average responses. We used OLS regression to identify the more popular specific types or topics of the posts for the three cities on a daily basis.

\section{Results}

\subsection{RQ1 and RQ2: Differences in Posts and User Responses}

To answer RQ1 and 2, we explored differences between the cities in government posts and the user responses the posts attracted. During the two months observed, Shanghai's information account posted a total of 1,298 messages; these posts received 81,213 user responses, including 30,501 likes, 29,396 shares and 21,316 comments. Nanjing's information account posted 943 messages which received 127,728 user responses, including 50,391 likes, 33,883 shares and 43,454 comments. Chengdu's information account posted 2,188 messages, receiving 194,823 user responses, including 99,419 likes, 51,124 shares and 44,280 comments.

Table 1 presents information about posting types. The type with the largest volume for Shanghai is Guidance at 413 posts $(31.8 \%)$, which received the most user responses $(22,602)$. It is followed by Reminders $(27.3 \%)$ and Publicity (18.3\%). Interaction $(14,1.1 \%)$ and Other $(10,0.8 \%)$ are the least, the latter only received 349 user responses. For Nanjing, Publicity information was posted 273 times $(29 \%)$, and also received the most user responses $(39,662)$. It is followed by Guidance (24.6\%) and Interaction (22.5\%). The smallest posting type is Information disclosure (34, $3.6 \%$ ), and user responses were also the least $(3,294)$. For Chengdu, the type with the largest posting volume is Guidance as in Shanghai, with 713 posts $(32.6 \%)$, and 67,072 user responses obtained. It is followed by Publicity (20.2\%). The smallest posting type is Information Disclosure $(95,4.3 \%)$, similar to Nanjing, with the fewest user responses $(4,535)$. Posts from the three cities are significantly different across the 7 release types $(\chi 2=730.879, \mathrm{p}<0.01, \mathrm{~N}=4429)$.

Table 1. Cross-tabulation of posts for cities and posting types

\begin{tabular}{rllllllll}
\hline & \multicolumn{9}{c}{ Info } & \multicolumn{5}{c}{ Announ Interac } \\
\cline { 2 - 6 } & \multicolumn{3}{c}{ Publicity Guidance disclosure Reminders } & cements tion & Other & Total \\
\hline SH Count & 238 & 413 & 131 & 354 & 138 & 14 & 10 & 1298 \\
$\%$ city & $18.3 \%$ & $31.8 \%$ & $10.1 \%$ & $27.3 \%$ & $10.6 \%$ & $1.1 \%$ & $0.8 \%$ & $100.0 \%$ \\
NJ Count & 273 & 232 & 34 & 47 & 92 & 212 & 53 & 943 \\
$\%$ city & $29.0 \%$ & $24.6 \%$ & $3.6 \%$ & $5.0 \%$ & $9.8 \%$ & $22.5 \%$ & $5.6 \%$ & $100.0 \%$ \\
CD Count & 441 & 713 & 95 & 217 & 270 & 213 & 239 & 2188 \\
$\%$ city & $20.2 \%$ & $32.6 \%$ & $4.3 \%$ & $9.9 \%$ & $12.3 \%$ & $9.7 \%$ & $10.9 \%$ & $100.0 \%$ \\
Total Count 952 & 1358 & 260 & 618 & 500 & 439 & 302 & 4429 \\
$\%$ city & $21.5 \%$ & $30.7 \%$ & $5.9 \%$ & $14.0 \%$ & $11.3 \%$ & $9.9 \%$ & $6.8 \%$ & $100.0 \%$ \\
\hline
\end{tabular}

Note: SH: Shanghai; NJ: Nanjing; CD: Chengdu

Obviously, Guidance is used the most both in Shanghai and Chengdu. However, Nanjing most often posts information in the category of Publicity. It is noteworthy that Shanghai publishes more Reminders $(27.3 \%)$ while Nanjing posts requests for Interactions $(22.5 \%)$ from users. In general, Publicity and Guidance are more mainstream forms for the three cities $(50.1 \%$, $53.6 \%$, and $52.8 \%$ ). Chengdu posts more frequently by at least $20 \%$ in total and for many specific types, except that Information Disclosure (95) and Reminders (217) are lower than Shanghai (131 and 354). 
Table 2 presents results for posting topics used by each city. Due to space limitations, only the top 7 topics of posts in each city are shown ${ }^{1}$. The major topics of Shanghai's posts are Transportation (237, $18.3 \%$ ) and Art $(207,15.9 \%)$. User responses to the two types are also the most, more than 10,000 . They are followed by Government (11.2\%), Weather $(10.2 \%)$ and Health $(8.3 \%)$, with more than 100 releases. The major topics for Nanjing are Art $(179,19 \%)$, Society $(147,15.6 \%)$ and Tourism $(132,14 \%)$, all of which also have more user responses. The major topics for Chengdu are Society (251, 11.5\%) and Art (242, $11.1 \%$ ), and their user responses are both over 20,000, but in contrast, Art has more responses than Society. The remaining most released types, namely Government (9\%), Other (8.8\%), Food (8.6\%), Life $(8.5 \%)$ and Transportation $(7.9 \%)$, also have a high volume of posts, all close to 200 . The chi-square test result shows that the posts from the three cities are significantly different across the 16 release topics $(\chi 2=921.012, \mathrm{p}<0.01, \mathrm{~N}=4429)$.

The three cities post information in markedly different topic areas, although there are some similarities across cities. Transportation (18.3\%), Art $(19 \%)$ and Society $(11.5 \%)$ are among the top subjects from Shanghai, Nanjing and Chengdu. However, the distribution is dispersed as each of the most posted topics are less than $20 \%$. Art and Transportation are common interests of the cities.

\subsection{RQ3: Analysis of User Responses}

RQ3 asked if the level of user response varies between the three cities depending on type or topic. Tables 3 and 4 show the results. Given the differences in posting frequencies between the cities, we normalized responses by displaying the average number of response to posts of each type or topic. The total average number of public responses in the three cities across the 7 release types are 426 (Shanghai), 832 (Nanjing) and 588 (Chengdu).

The chi-square test result shows that the average public response for the three cities are significantly different across the 7 release types $(\chi 2=120.632$, $\mathrm{p}<0.01, \mathrm{~N}=1846$ ). Within cities, by comparing likes, shares and comments, there is no significant difference for Shanghai in average responses to posting types $(\chi 2=14.096, p=0.295, \mathrm{~N}=426)$. However, there are significant differences in the average responses for posting types for Nanjing $(\chi 2=77.077, \mathrm{p}<0.01, \mathrm{~N}=832)$ and Chengdu $(\chi 2=86.018, \mathrm{p}<0.01, \mathrm{~N}=588)$.

\footnotetext{
${ }^{1}$ The author can provide information about the other topics and related data.
}

From Table 3, for Shanghai, Announcements (90, $21.1 \%)$ and Publicity $(81,19 \%)$ receive the greatest average public responses followed by Interaction (14.3\%), Guidance (12.9\%), and Reminders (12.9\%). Other $(35,8.2 \%)$ is the least. For Nanjing, Interaction receives the highest average public responses (162, $19.5 \%$ ), followed by Publicity (17.4\%), and Guidance $(16.2 \%)$. Reminders $(79,9.5 \%)$ is the least. For Chengdu, Announcements receives the greatest average public responses $(196,33.3 \%)$, followed by Guidance (16.2\%) and Interaction (15.8\%). Reminders $(38,6.5 \%)$ is also the least. The citizens of Shanghai

Table 2. Cross-tabulation of posts for cities and posting topics

\begin{tabular}{|c|c|c|c|c|c|c|c|c|}
\hline & \multicolumn{8}{|c|}{ topic } \\
\hline & \multicolumn{3}{|c|}{ Transpo } & \multirow[b]{2}{*}{ Weather } & \multicolumn{3}{|c|}{ Environ Employ } & \multirow[b]{2}{*}{ Total } \\
\hline & rtation & Art & Government & & Health & o ment & ment & \\
\hline SHCount & 237 & 207 & 145 & 132 & 108 & 79 & 70 & 978 \\
\hline \multirow[t]{3}{*}{$\%$ city } & $18.3 \%$ & $15.9 \%$ & $11.2 \%$ & $10.2 \%$ & $8.3 \%$ & $6.1 \%$ & $5.4 \%$ & $75.4 \%$ \\
\hline & \multicolumn{8}{|c|}{ topic } \\
\hline & Art & Society & Tourism & Education & Life & $\begin{array}{l}\text { Transpo } \\
\text { rtation }\end{array}$ & Other & Total \\
\hline NJ Count & $\overline{179}$ & 147 & 132 & 78 & 67 & 51 & 51 & 705 \\
\hline \multirow[t]{3}{*}{$\%$ city } & $19.0 \%$ & $15.6 \%$ & $14.0 \%$ & $8.3 \%$ & $7.1 \%$ & $5.4 \%$ & $5.4 \%$ & $74.8 \%$ \\
\hline & \multicolumn{8}{|c|}{ topic } \\
\hline & Society & Art & Government & Other & Food & Life & $\begin{array}{l}\text { Transpo } \\
\text { rtation }\end{array}$ & Total \\
\hline CD Count & $\overline{251}$ & 242 & 196 & 192 & 188 & 185 & 172 & 1426 \\
\hline$\%$ city & $11.5 \%$ & $11.1 \%$ & $9.0 \%$ & $8.8 \%$ & $8.6 \%$ & $8.5 \%$ & $7.9 \%$ & $65.4 \%$ \\
\hline
\end{tabular}

Table 3. Cross-tabulation of average user responses for cities and posting types

\begin{tabular}{rllllllll}
\hline & \multicolumn{9}{c}{ type } \\
\cline { 2 - 6 } & \multicolumn{3}{c}{ Info } & \multicolumn{5}{c}{ Announ Interac } \\
\hline SH Count & 81 & 55 & 49 & 55 & 90 & 61 & 35 & 426 \\
$\%$ city & $19.0 \%$ & $12.9 \%$ & $11.5 \%$ & $12.9 \%$ & $21.1 \%$ & $14.3 \%$ & $8.2 \%$ & $100.0 \%$ \\
NJ Count & 145 & 135 & 97 & 79 & 100 & 162 & 114 & 832 \\
$\%$ city & $17.4 \%$ & $16.2 \%$ & $11.7 \%$ & $9.5 \%$ & $12.0 \%$ & $19.5 \%$ & $13.7 \%$ & $100.0 \%$ \\
CD Count & 70 & 95 & 48 & 38 & 196 & 93 & 48 & 588 \\
$\%$ city & $11.9 \%$ & $16.2 \%$ & $8.2 \%$ & $6.5 \%$ & $33.3 \%$ & $15.8 \%$ & $8.2 \%$ & $100.0 \%$ \\
Total Count & 296 & 285 & 194 & 172 & 386 & 316 & 197 & 1846 \\
$\%$ city & $16.0 \%$ & $15.4 \%$ & $10.5 \%$ & $9.3 \%$ & $20.9 \%$ & $17.1 \%$ & $10.7 \%$ & $100.0 \%$ \\
\hline
\end{tabular}

Note: SH: Shanghai; NJ: Nanjing; CD: Chengdu

and Chengdu are most interested in Announcements $(21.1 \%$ and $33.3 \%)$. In contrast, Nanjing citizens choose Interaction (19.5\%). Additionally, Publicity receives more average response both in Shanghai (19\%) and Nanjing (17.4\%) while Chengdu corresponds to Guidance $(16.2 \%)$ and Interaction $(15.8 \%)$. Comparing the three cities, all the average user responses in Shanghai are below 100. Nanjing's average response has surpassed all other cities, except for Announcements (100) which is below Chengdu (196), but still higher than that of Shanghai (90). 
In Table 4, again space limits us to present the 7 topics with the highest average response for each city. The chi-square test shows that the average public response from the three cities are significantly different across the 16 release topics $(\chi 2=434.557, \mathrm{p}<0.01$, $\mathrm{N}=4535$ ). The total average number of responses in the three cities are 1055 (Shanghai), 2056 (Nanjing) and 1424 (Chengdu), separately. Within cities, by comparing likes, shares and comments, there is no significant difference $(\chi 2=42.113, p=0.07, \mathrm{~N}=1055)$ in the average public responses to different topic categories for Shanghai. However, there are significant differences in the average public responses for Nanjing $(\chi 2=132.693, \mathrm{p}<0.01, \mathrm{~N}=2056)$ and for Chengdu $(\chi 2=124.394, \mathrm{p}<0.01, \mathrm{~N}=1424)$.

\section{Table 4. Cross-tabulation of average user responses for cities and posting topics}

\begin{tabular}{|c|c|c|c|c|c|c|c|c|}
\hline & \multicolumn{7}{|c|}{ topic } & \multirow{3}{*}{$\begin{array}{l}\text { Total } \\
657\end{array}$} \\
\hline \multirow{2}{*}{$\overline{\mathrm{SH} \text { Count }}$} & \multirow{2}{*}{$\begin{array}{l}\text { Sports } \\
196\end{array}$} & \multirow{2}{*}{$\begin{array}{l}\text { Health } \\
90\end{array}$} & \multicolumn{2}{|c|}{ Education Tourism } & \multicolumn{2}{|c|}{ Weather Other } & \multirow{2}{*}{$\begin{array}{l}\text { Life } \\
63\end{array}$} & \\
\hline & & & 87 & 79 & 71 & 71 & & \\
\hline \multirow[t]{3}{*}{$\%$ city } & $18.6 \%$ & $8.5 \%$ & $8.2 \%$ & $7.5 \%$ & $6.7 \%$ & $6.7 \%$ & $6.0 \%$ & $62.2 \%$ \\
\hline & \multicolumn{7}{|c|}{ topic } & \\
\hline & Recreation & Other & Art & Education & Food & $\begin{array}{l}\text { Transpo } \\
\text { rtation }\end{array}$ & ${ }^{0}$ Tourism & Total \\
\hline NJ Count & 212 & 177 & 150 & 144 & 136 & 135 & 129 & 1083 \\
\hline \multirow[t]{3}{*}{$\%$ city } & $10.3 \%$ & $8.6 \%$ & $7.3 \%$ & $7.0 \%$ & $6.6 \%$ & $6.6 \%$ & $6.3 \%$ & $52.7 \%$ \\
\hline & \multicolumn{7}{|c|}{ topic } & \\
\hline & Sports & \multicolumn{2}{|c|}{ Education Industry } & Art & Society & Food & Recreation & Total \\
\hline CDCount & 235 & 143 & 137 & 120 & 103 & 92 & 92 & 922 \\
\hline$\%$ city & $16.5 \%$ & $10.0 \%$ & $9.6 \%$ & $8.4 \%$ & $7.2 \%$ & $6.5 \%$ & $6.5 \%$ & $64.7 \%$ \\
\hline
\end{tabular}

Note: SH: Shanghai; NJ: Nanjing; CD: Chengdu

For Shanghai, Sports receives the highest average public responses per post $(196,18.6 \%)$, but the average response of the next 6 topics starting from Health $(8.5 \%)$ drops to less than 100 . For Nanjing, Recreation receives the greatest average public response (212, $10.3 \%$ ). The other 6 highest topics also received over 100 average responses. For Chengdu, Sports has the highest average response $(235,16.5 \%)$, followed by Education (10\%), Industry (9.6\%), Art (8.4\%) and Society (7.2\%). Sports is undoubtedly the most popular topic both in Shanghai and Chengdu. Similar to average responses by type, Nanjing receives more average user responses for almost all the top 7 topics than the other cities.

\subsection{RQ4: Consistency between Posts and Response}

After analyzing the government posts and citizen response separately, RQ4 addressed the relationship between them and explored whether they vary in the same direction, or vice versa, or no impact.

4.3.1. Pearson correlation analysis. Our analysis showed there is a significant positive correlation between the total number of responses to posts of different types or topics of the three cities and the corresponding number of government posts. As the number of posts in a category increases, the responses for each city also increases for both types and topics. However, this relationship reflects the cumulative effect of posts, that is, the response increases with greater numbers of posts. In further exploration, we find no significant correlation between the average responses to different types or topics and the number of government posts, except for Nanjing, for which we find a significant positive correlation $(r=0.862, n=7$, $\mathrm{p}<0.05$ ) only between posting type and average user response. The latter more accurately represents whether government posts are related to user responses. Only for Nanjing do we find consistency between government posts and public responses across posting type.

4.3.2. OLS linear regression analysis. We further analyzed the relationship between the daily user responses and the posting volume of types or topics in each city according to the collection period of 61 days by using OLS regression. To better satisfy the regression conditions, the dependent variable was log transformed, and thus regression coefficients can be interpreted as percentage ${ }^{2}$.

The regressions show that the relationship between different types of posts and the daily response is significant both in Shanghai and Nanjing, but not for Chengdu $(\mathrm{F}=1.854, \mathrm{p}=0.096)$. Please see Table 5. To be more specific, Publicity and Guidance have a significant impact on the daily user response in Shanghai. Every additional release of Publicity per day will increase the average response by $3.9 \%$; every additional release of Guidance per day will increase the average response by $1.5 \%$. For Nanjing, there are five types that have a significant impact on the daily user response, namely Publicity, Guidance, Reminders, Announcements and Interaction.

Table 6 only presents the regression results of Nanjing, because there is no effect of topic on the daily response from users in Shanghai $(\mathrm{F}=1.779, \mathrm{p}=0.066)$ and Chengdu $(\mathrm{F}=1.601, \mathrm{p}=0.109)$. There are significant relationships between the daily response and different topics of posts in Nanjing for the topics of Transportation, Food, Sports, Tourism, Environment, Art, Recreation, Society and Industry.

Table 5. Linear regression results by types

\begin{tabular}{|c|c|c|}
\hline & $\begin{array}{c}\text { Shanghai } \\
\text { Coefficients }\end{array}$ & $\begin{array}{c}\text { Nanjing } \\
\text { Coefficients }\end{array}$ \\
\hline Model & Std. Error & Std. Error \\
\hline
\end{tabular}

${ }^{2}$ Please see: https://stats.idre.ucla.edu/sas/faq/how-can-i-interpretlog-transformed-variables-in-terms-of-percent-change-in-linearregression/ 


\begin{tabular}{lllll}
\hline (Constant) & $2.711 * * *$ & .105 & $2.854 * * *$ & .091 \\
Publicity & $.039 *$ & .016 & $.033^{* * *}$ & .010 \\
Guidance & $.015 * *$ & .005 & $.034 * * *$ & .010 \\
Information... & .010 & .017 & .023 & .017 \\
Reminders & .002 & .009 & $.028^{*}$ & .014 \\
Announce... & .036 & .019 & $.026 *$ & .012 \\
Interaction & .047 & .040 & $.025^{*}$ & .012 \\
Other & -.033 & .062 & .007 & .018 \\
R Square & .270 & & .371 & \\
Adjusted R & .173 & & .288 & \\
Square & & & $4.463 * * *$ & \\
$\quad \mathrm{~F}$ & $2.798 *$ & &
\end{tabular}

Note: Dependent Variable: log_response

${ }^{*} p<.05 ;{ }^{* *} p<.01 ;{ }^{* *} p<.001$

Table 6. Linear regression results by topics

\begin{tabular}{lll}
\hline Model & \multicolumn{2}{l}{ Nanjing Coefficients } \\
& $\mathrm{B}$ & Std. Error \\
\hline (Constant) & $2.794^{* * *}$ & .094 \\
Transportation & $.052^{* *}$ & .018 \\
Education & .026 & .016 \\
Health & .025 & .025 \\
Food & $.059^{*}$ & .022 \\
Weather & -.029 & .024 \\
Sports & $.079^{*} *$ & .026 \\
Tourism & $.033^{*}$ & .013 \\
Environment & $.104 *$ & .042 \\
Employment & .044 & .044 \\
Art & $.032^{* *}$ & .010 \\
Recreation & $.068^{* *}$ & .022 \\
Society & $.034^{* *}$ & .011 \\
Life & .020 & .017 \\
Government & -.014 & .020 \\
Industry & $.057^{*}$ & .022 \\
Other & .016 & .017 \\
R Square & .569 & \\
Adjusted R Square & .412 & \\
F & $3.628^{* * *}$ & \\
\hline
\end{tabular}

Note: Dependent Variable: log_response

${ }^{*} p<.05 ;{ }^{* *} p<.01 ;{ }^{* * *} p<.001$

\section{Discussion}

As expected, an analysis of RQ1 indicates that Guidance is a vital goal for the government social media accounts in China. Guidance has become the most typical type of release in Shanghai and Chengdu. However, the cities are also interested in Publicity, a type which receives many posts. It appears that municipal governments in China are gradually paying more attention to public service, reflected in increasing use of Reminders in Shanghai. At the same time, Nanjing frequently attempts to interact with the public in two-way communication, unlike other cities.

The data of RQ2 shows that the postings of each city focus on multiple topics, which reflects the comprehensive coverage of content selection of these cities in China. Moreover, different cities emphasize different topic choices. For example, Shanghai focuses on transportation, government affairs, weather and health. Nanjing mainly pays attention to art, society and tourism. Chengdu focuses on society, government affairs, food, life, and others. The reasons may be related to the distinct social, economic and cultural characteristics of each city. As the largest metropolis compared to the others, traffic and weather attract attention in Shanghai. Nanjing's rich historical and humanistic resources are featured in more art and tourism information while Chengdu emphasizes a special food culture and lifestyle.

From RQ3, the average responses in 7 different release types indicate that public participation in Nanjing is the highest, followed by Chengdu and Shanghai. Users in Shanghai and Chengdu like to respond to Announcements posts most, perhaps because of the splendid exhibitions, performances and competitions in Shanghai and Chengdu. Interaction posts in Nanjing are very attractive, which demonstrates efforts to strengthen communication through interactive posts to elicit feedback from citizens, with relatively successful effects.

User responses from the three cities on 16 topics is similar to that of the types. The highest participation is still Nanjing, followed by Chengdu and Shanghai. The citizens of Shanghai and Chengdu show a common interest in the topic of Sports, which may be related to the incentives of sports events during the observation period, such as Shanghai's championship of the 2018 Chinese Football Association Super League, Shanghai's Tennis Masters Competition, and Chengdu's Marathon. Nanjing citizens prefer leisure and art. Education is a livelihood topic that the three cities are more concerned about. The reaction of citizens to other topics is quite different.

RQ4 attempts to link the posts and responses in the first three research questions. As the volume of posting increases, user responses in each city increase accordingly, reflecting the general encouragement and follow-up attitude of users to the government posts. Whenever the city government exercises voice, the citizens will always respond by means of likes, shares or comments. However, in terms of the average response to each type or topic of posts, most of them are not related to the posting categories of the municipal government. To some extent, this indicates that these types or topics have not yet attracted more interest from users. The only exception is the performance of Nanjing in posting type, which further establishes the comparative advantage of Nanjing government social media.

In assessing the relationship between posts with different types or topics and the daily user response, Nanjing still has the best consistency, followed by 
Shanghai. Nanjing has shown more significant relationships with daily user response in both types and topics. The highlighted types, such as Guidance and Publicity, as well as key topics, such as Art, Recreation, and Society have also received more responses. Shanghai only shows a positive relationship with the daily user responses in the type of Guidance and Publicity, while Chengdu's posting types or topics are not related to daily user responses.

Overall, the study yields some interesting results. From the total amount of government postings, Chengdu is the most, Shanghai is the second, and Nanjing is the least. In terms of the total response, Chengdu is the most popular, followed by Nanjing and Shanghai. However, from the average user response of different types or topics, Nanjing is the most, followed by Chengdu and Shanghai. It can be seen that for the amount of government action, the information account of Chengdu is the most proactive, trying to promote open government and communication with citizens through a large number of posts. Its release volume is more than twice that of Nanjing. However, from the perspective of the effectiveness of government social media, although the total response of Chengdu public is large, there is no apparent relationship between posting behavior and user response for type or topic, in the analysis by day. Therefore, Nanjing's performance is the best in citizen engagement. It not only has the highest average response rate for almost each type or topic, but also many types and topics of daily postings have aroused attention, which confirms the most successful interaction between the government and the public. The overall performance in Shanghai is moderate. It is worth mentioning that Publicity and Guidance released daily can significantly affect the public, but the problem is that both total user response and average user response are relatively small, despite the fact that Shanghai is a large and international city.

In short, Chinese municipal governments, as represented by Shanghai, Nanjing and Chengdu, have launched beneficial attempts to use social media platforms by posting various types of messages on a daily basis, covering many different topic areas. Correspondingly, a large number of user responses indicated by likes, shares and comments, have been harvested. However, it appears that the push mechanism still promotes one-way communication, that is, the government has focused on Guidance and Publicity for its own goals. User needs and interest derived from geography, culture or social changes are easily overlooked. The government should pay attention to these characteristics, and the relationship between the posts and public response, meet the needs of users [16][10], innovate the content of posts, and prevent overload or even negative effects of government information caused by irrelevance. The type of Interaction is a government attempt for twoway interaction. Although it is usually not one of the most important types for posting, the positive response by users in Nanjing indicates a strong desire for political interaction from the government and citizens.

There are some important shortcomings in this paper. Our study of the relationship between government posts and user responses only considers the impact of different types or topics, but does not involve other possible factors [11][12][28], such as posting format, time, discourse structure, etc.. In addition, the data is limited to two natural months, without considering the average impact of long-term cycles and the possible impact of the specific time period on the results. Moreover, the measurement of response mainly uses the added values of likes, shares and comments, and does not explore the individual metrics of the responses. More importantly, user participation is also reflected in the user's specific comments. Further text analysis is required to more accurately represent the user's opinion.

\section{Conclusions}

What does this data tell us about democratic participation in government social media? The use of government microblogs in these three Chinese cities provides a good example of experimental "betainstitutions" [23] in that they show variations in interaction between government employees and netizens in the microblog space that may well be the result of different municipal strategies. The total responses of the public are large, but the average response of each city for different types or topics is significantly different, which shows the public's appetite for specific types or topics. At the same time, the limited relationship between posts and responses also illustrates that the government has a long way to go in attracting citizens' feedback and achieving twoway communication goals. It is necessary to fully explore user needs [16][10] and optimize the content to produce posts with positive responses and promote sustainable development of municipal government social media in a virtuous circle. Future researchers may consider incorporating more government social data, discovering its regularity across time, and more factors that influence user response, such as communicative form, discourse style, etc., and deeply analyzing the implications of the message text, especially for sentiment of public participation.

\section{References}


[1] Agostino, D., and Arnaboldi, M., "A Measurement Framework for Assessing the Contribution of Social Media to Public Engagement: An Empirical Analysis on Facebook", Public Management Review, 2016, 18(9), pp. 1289-1307.

[2] Bonsón, E., Royo, S., and Ratkai, M., "Citizens' Engagement on Local Governments' Facebook Sites. An Empirical Analysis: The Impact of Different Media and Content Types in Western Europe", Government Information Quarterly, 2015, 32(1), pp. 52-62.

[3] Chen, H.M., and Franks, P.C., "Exploring Government Uses of Social Media through Twitter Sentiment Analysis", Journal of Digital Information Management, 2016, 14(5), pp. 290-301.

[4] DePaula, N., and Dincelli, E., "An Empirical Analysis of Local Government Social Media Communication: Models of E-government Interactivity and Public Relations", Proceedings of the 17th International Digital Government Research Conference on Digital Government Research, Shanghai, China: ACM New York, 2016, pp. 348-356.

[5] DePaula, N., Dincelli, E., and Harrison, T.M., "Toward a Typology of Government Social Media Communication: Democratic Goals, Symbolic Acts and Self-presentation", Government Information Quarterly, 2018, 35(1), pp. 98-108. [6] DePaula, N., and Dincelli, E., "Information Strategies and Affective Reactions: How Citizens Interact with Government Social Media Content”, First Monday, 2018, 23(4), Retrieved from

https://journals.uic.edu/ojs/index.php/fm/article/view/8414/6 695\#author.

[7] Gálvez-Rodríguez, M.d.M, Sáez-Martín, A., GarcíaTabuyo, M., and Caba-Pérez, C., "Exploring Dialogic Strategies in Social Media for Fostering Citizens' Interactions with Latin American Local Governments", Public Relations Review, 2018, 44(2), pp. 265-276.

[8] General Office of the CPC Central Committee, and General Office of the State Council of the People's Republic of China, Comprehensively Promoting the Openness of Government, Beijing, China, 2016.

[9] General Office of the State Council of the People's Republic of China. Further Strengthening Government Information Disclosure in Response to Social Concerns and Enhancing Government Credibility, Beijing, China, 2013.

[10] Guo, J., Liu, Z., and Liu, Y., "Key Success Factors for the Launch of Government Social Media Platform: Identifying the Formation Mechanism of Continuance Intention", Computers in Human Behavior, 2016, 55(Part B), pp. $750-763$.

[11] Hao, X., Zheng D., and Zeng Q., "How to Strengthen the Social Media Interactivity of E-government Evidence from China", Online Information Review, 2016, 40(1), pp. 79-96.

[12] Hofmann, S., Beverungen, D., Räckers, M., and Becker, J., "What Makes Local Governments' Online Communications Successful? Insights from a Multi-method Analysis of Facebook", Government Information Quarterly, 2013, 30(4), pp. 387-396.

[13] King G., Pan J., and Roberts M. E., "How Censorship in China Allows Government Criticism but Silences Collective Expression", American Political Science Review, 2012, 107(2), pp. 326-343.
[14] Lappas, G., Triantafillidou, A., Deligiaouri, A., and Kleftodimos, A., "Facebook Communication Strategies and Their Effectiveness: A Case Study of Greek Local Municipal Governments", Proceedings of the 4th Multidisciplinary International Social Networks Conference. Bangkok, Thailand: ACM NY, 2017, pp. 1-6.

[15] Lev-On, A., and Steinfeld, N., "Local Engagement Online: Municipal Facebook Pages as Hubs of Interaction", Government Information Quarterly, 2015, 32(3), pp. 299-307. [16] Li, Y., Yang, S., Chen, Y., and Yao J., "Effects of Perceived Online-offline Integration and Internet Censorship on Mobile Government Microblogging Service Continuance: A Gratification Perspective". Government Information Quarterly, 2018,35(4), pp. 588-598.

[17] Medaglia, R., and Zhu, D., "Public Deliberation on Government-managed Social Media: A Study on Weibo Users in China", Government Information Quarterly, 2017, 34(3), pp. 533-544.

[18] Mergel, I., “A Framework for Interpreting Social Media Interactions in the Public Sector", Government Information Quarterly, 2013, 30(4), pp. 327-334.

[19] Mossberger, K., Wu, Y., and Crawford, J., "Connecting Citizens and Local Governments? Social Media and Interactivity in Major U.S. Cities", Government Information Quarterly, 2013,30(4), pp. 351-358.

[20] Public Opinion Data Center of People.cn, 2016 People's Daily: Government Index, Microblog Influence Report, Beijing, China, 2017.

[21] Public Opinion Data Center of People.cn, 2017 People's Daily: Government Index, Microblog Influence Report. Beijing, China, 2018.

[22] Public Opinion Data Center of People.cn, 2018 People's Daily: Government Index, Microblog Influence Report. Beijing, China, 2019.

[23] Schlæger J., and Jiang M., "Official Microblogging and Social Management by Local Governments in China", China Information, 2014, 28(2), pp. 189-213.

[24] Su, Z., and Meng, T., "Selective Responsiveness: Online Public Demands and Government Responsiveness in Authoritarian China”, Social Science Research, 2016, 59, pp. 52-67.

[25] The Central Leading Group for Comprehensive and Deepening Reform, Guidance on Promoting the Integration of Traditional and Emerging Media, Beijing, China, 2014.

[26] Wukich, C., and Mergel, I., "Closing the CitizenGovernment Communication Gap: Content, Audience, and Network Analysis of Government Tweets", Homeland Security \& Emergency Management, 2015, 12(3), pp. 707735 .

[27] Zavattaro, S.M., French, P.E., and Mohanty, S.D., "A Sentiment Analysis of U.S. Local Government Tweets: The Connection between Tone and Citizen Involvement", Government Information Quarterly, 2015, 32(3), pp. 333-341. [28] Zheng, L., and Zheng, T., "Innovation through Social Media in the Public Sector: Information and Interactions", Government Information Quarterly, 2014, 31(S1), pp. 106117. 